\title{
Pelatihan Pembuatan Media Pembelajaran Matematika di SD Negeri Jatimekar 02
}

\author{
Sri Awan Asri $1^{*}$, A. Rahim², Ilmi Noor Rahmad ${ }^{3}$ \\ 1,2,3 STKIP Kusuma Negara, Jakarta, Indonesia \\ *Corresponding Author: sriawanasri@stkipkusumanegara.ac.id
}

\begin{abstract}
Info Artikel
Diterima : 03/01/2021

Direvisi: 29/01/2021

Disetujui: $21 / 02 / 2021$

Abstract. In general, elementary school age children (SD) are experiencing development at their thinking level, elementary school children's thinking stages are still not formal and are still concrete in nature. Therefore, the teacher must present material that is real so that elementary students can understand the concept completely. Based on the results of interviews with several mathematics teachers and principals, information was obtained that mathematics learning is carried out very rarely using media, especially in the form of props or other innovative media. Regarding the above problems, we are interested in conducting training through a community service program entitled "PKM Training on Making Mathematics Learning Media at SDN Jatimekar 02." This PKM is carried out in the form of three meetings training. The training participants were a number of teachers at SDN Jatimekar 02 Pagi. The presentation material in this service activity is: (1) The concept of learning media that is in accordance with the characteristics of Mathematics subjects along with examples of implementation in learning (2) Making learning implementation plans (RPP) with appropriate learning media (3) Simulation of implementing cooperative learning media in learning, and (4) assessment of learning using instructional media. Based on the results of the evaluation, 28 out of 32 participants understood the concept of learning media well, 25 participants were able to develop plans for implementing learning using media, and 30 participants were able to use media when learning in class.
\end{abstract}

Keywords: Training, Media, Mathematics.

\begin{abstract}
Abstrak. Pada umunya anak usia Sekolah Dasar (SD) sedang mengalami perkembangan pada tingkat berpikirnya, tahapan berfikir anak SD masih belum formal dan masih bersifat konkret. Oleh sebab itu guru harus menyajikan materi yang bersifat nyata agar siswa SD dapat memahmai konsep secara utuh. Berdasarkan hasil wawancara dengan beberapa guru matematika dan kepala sekolah diperoleh informasi bahwa pembelajaran matematika yang dilaksanakan sangat jarang menggunakan media, khususnya yang berupa alat peraga ataupun media-media inovatif lainnya. Terkait permasalahan di atas, maka kami tertarik untuk melalukan pelatihan melalui program pengabdian kepada masyarakat dengan Judul "PKM Pelatihan Pembuatan Media Pembelajaran Matematika di SDN Jatimekar 02.” PKM ini dilaksanakan dalam bentuk pelatihan tiga pertemuan. Peserta pelatihan sejumlah guru SDN Jatimekar 02 Pagi. Materi sajian dalam kegiatan pengabdian ini yaitu: (1) Konsep media pembelajaran yang sesuai dengan karakteristik mata pelajaran Matematika beserta contoh pelaksanaan dalam pembelajaran (2) Pembuatan rencana pelaksanaan pembelajaran (RPP) dengan media pembelajaran yang sesuai (3) Simulasi pelaksanaan media pembelajaran kooperatif dalam pembelajaran, serta (4) Penilaian pembelajaran dengan menggunakan media pembelajaran. Berdasaekan hasil evaluasi sebanyak 28 dari 32 peserta memahami konsep media pembelajaran dengan baik, sebanyak 25 peserta mampu mengembangkan rencana pelaksanaan pembelajaran menggunakan media, dan 30 orang peserta mampu menggunakan media pada saat pembelajaran dikelas.
\end{abstract}

Kata Kunci: Matematika. Pelatihan, Media, Matematika.

How to Cite: Asri, S. A., Rahim, A., \& Rahmad, I. N. (2021). Pelatihan Pembuatan Media Pembelajaran Matematika di SD Negeri Jatimekar 02. Prima Abdika: Jurnal Pengabdian Masyarakat, 1(1), $20-25$. https://doi.org/10.37478/abdika.v1i1.938

\section{Pendahuluan}

Belajar matematika harus melalui proses yang bertahap dari konsep yang sederhana ke konsep yang lebih kompleks. Dian Novitasari (2016) mengatakan Konsep-konsep dalam matematika memiliki keterkaitan satu dengan yang lainnya. Saling keterkaitannya antar konsep materi satu dan yang lainnya merupakan bukti akan pentingnya pemahaman konsep matematika. Karenanya, siswa belum bisa memahami suatu materi jika 
belum memahami materi sebelumnya atau materi prasyarat dari materi yang akan pelajari

Pada umunya anak usia Sekolah Dasar (SD) sedang mengalami perkembangan pada tingkat berpikirnya, tahapan berfikir anak SD masih belum formal dan masih bersifat konkret. Oleh sebab itu guru harus menyajikan materi yang bersifat nyata agar siswa SD dapat memahmai konsep secara utuh Nanang (2018). Suparno (2002) berpendapat bahwa Anak mampu mengerti adanya perpindahan pada hal yang konkret serta sudah memahami persoalan sebab akibat, anak mampu memaknai suatu tindakan dianggap baik atau buruk dari akibat yang ditimbulkan.

Namun hal tersebut akan terjadi apabila proses pembelajaran dibantu menggunakan media sebagai alat yang dapat mempermudah guru sebagaimana pendapat Abdul Wahid (2018) Media pengajaran diartikan sebagai segala sesuatu yang dapat digunakan untuk menyalurkan pesan atau isi pelajaran, merangsang pikiran, perasaan, perhatian dan kemampuan peserta didik, sehingga dapat mendorong proses belajar mengajar. pendapat diatas dapat ditarik kesimpulan bahwa media merupakan alat yang penting digunakan oleh guru dan dengan adanya media akan memudahkan proses transfer infomasi dari guru ke siswa sehingga siswa lebih memahmi materi yang disampaikan.

Berdasarkan hasil wawancara dengan beberapa guru matematika dan kepala sekolah dasar diperoleh informasi bahwa pembelajaran matematika yang dilaksanakan sangat jarang menggunakan media, khususnya yang berupa alat peraga ataupun media-media inovatif lainnya. Siswa belajar matematika lebih banyak melalui penjelasan secara langsung oleh guru yang didominasi dengan pemberian ceramah. Padahal anak SD sangat membutuhkan pembelajaran menggunakan media konkrit untuk lebih memahami materi matematika karena siswa baru sampai tahap berpikir konkrit. Anak usia SD juga masih membutuhkan belajar yang menyenangkan, belajar yang monoton membuat siswa bosan dan tidak berminat dalam belajar. Media pembelajaran yang menarik merupakan salah satu alternatif membuat belajar menjadi menyenangkan. Keterampilan guru untuk merancang media pembelajaran matematika dan juga sangat kurang. Sebagai akibatnya siswa belajar matematika dengan cara-cara yang kurang bermakna. Siswa cenderung menghafal konsep atau prosedur tertentu dan belajar matematika lebih banyak secara mekanistik. Hal tersebut berdampak pada rendahnya prestasi belajar matematika. Terkait permasalahan di atas, maka kami tertarik untuk melalukan pelatihan melalui program pengabdian kepada masyarakat dengan judul "PKM Pelatihan Pembuatan Media Pembelajaran Matematika di SDN Jatimekar 02."

\section{Metode Pelaksanaan}

PKM ini dilaksanakan dalam bentuk pelatihan tiga pertemuan. Peserta pelatihan sejumlah guru SDN Jatimekar 02 Pagi. Materi sajian dalam kegiatan pengabdian ini yaitu: (1) Konsep media pembelajaran yang sesuai dengan karakteristik mata pelajaran Matematika beserta contoh pelaksanaan dalam pembelajaran (2) Pembuatan rencana pelaksanaan pembelajaran (RPP) 
dengan media pembelajaran yang sesuai (3) Simulasi pelaksanaan media pembelajaran kooperatif dalam pembelajaran, serta (4) Penilaian pembelajaran dengan menggunakan media pembelajaran.

Adapun media-media yang digunakan dalam pelatihan ini yakni sebagai berikut: Media teks, media visual, media audio visual, media proyeksi gerak, media benda-benda tiruan/miniature, dan manusia.

Langkah-langkah kegiatan PKM ini antara lain sebagai berikut:

1) Menyiapkan materi yang akan dipaparkan dalam PPT.

2) Menyusun jadwal kegiatan pelatihan yang direncanakan berlangsung 3 hari.

3) Menghubungi pihak sekolah untuk memastikan kesiapan guur-guru dilakukannya PKM.

4) Melakukan kegiatan PKM.

5) Melakukan evaluasi.

\section{Hasil dan Pembahasan}

Kegiatan Penyuluhan metode pembelajaran Matematika di SDN Jatimekar 02 ini secara singkat dapat diuraikan sebagai berikut:

Table 1. Hasil Pelatihan Pembuatan Media

\begin{tabular}{lcc}
\hline Hasil Pelatihan pembuatan Media & A & $\%$ \\
\hline Pemahaman Konsep Media Pembelajaran & 28 & 87,5 \\
Pengembangan Rencana Pelaksanaan Pembelajaran & 25 & 78,1 \\
Penggunaan Media dalam Pembelajaran & 30 & 93,7 \\
\hline
\end{tabular}

Berdasarkan tabel diatas dapat dijelaskan bahwa sebanyak 28 dari 32 peserta memahami konsep media pembelajaran dengan baik, sebanyak 25 peserta mampu mengembangkan rencana pelaksanaan pembelajaran menggunakan media, dan 30 orang peserta mampu menggunakan media pada saat pembelajaran dikelas. Hasil ini didapatkan setelah seluruh peserta mengikuti pelatihan pembuatan media, evaluasi yang digunakan berbentuk praktik pembuatan media dan aplikasinya dalam pembelajaran.

Antusiasme peserta yang tinggi dalam mengikuti pelatihan ini dikarenakan materi yang ditawarkan sangat sesuai dengan kebutuhan mereka sebagai guru SD. Media-media pembelajaran dianggap cukup efektif bagi peserta dalam memecahkan masalah-masalah pembelajaran pada umumnya yang cenderung menjadikan siswa SD pasif. Media pembelajaran yang tepat dapat meningkatkan kualitas pembelajaran, karena mampu meningkatkan kemauan dan partisipasi siswa dalam pembelajaran, memunculkan diskusi yang mengaktifkan kemampuan berfikir siswa, serta 
merangsaang kemampuan bekerjasama dan rasa tanggung jawab dari siswa SD. berdasarkan hasil observasi pada saat pelatihan berlangsung, diketahui bahwa peserta sudah cukup baik dalam hal perencanaan pembelajaran serta pelaksanaan pembelajaran dengan metode pembelajran yang ditetukan oleh guru. Selain itu, berdasarkan hasil visitasi, diketahui bahwa sebagian peserta pelatihan telah menerapkan metode pembelajaran tersebut pada pembelajaran di kelas masing-masing.

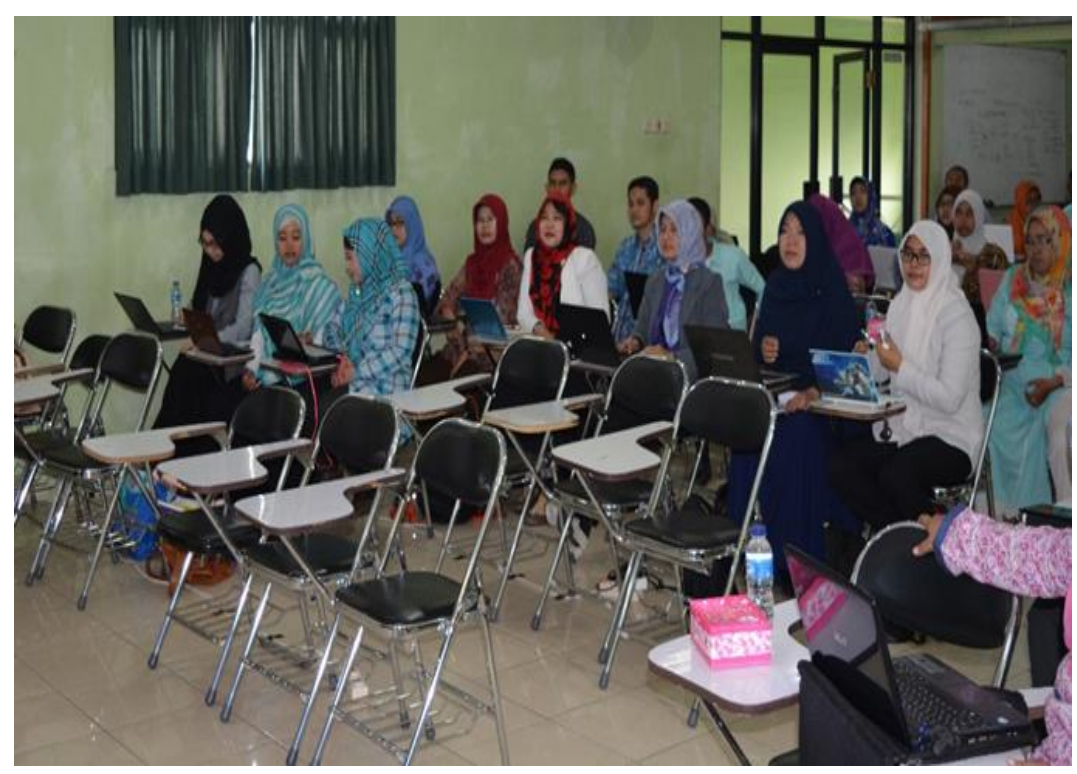

Gambar 1. Peserta PKM Menyimak Pemateri

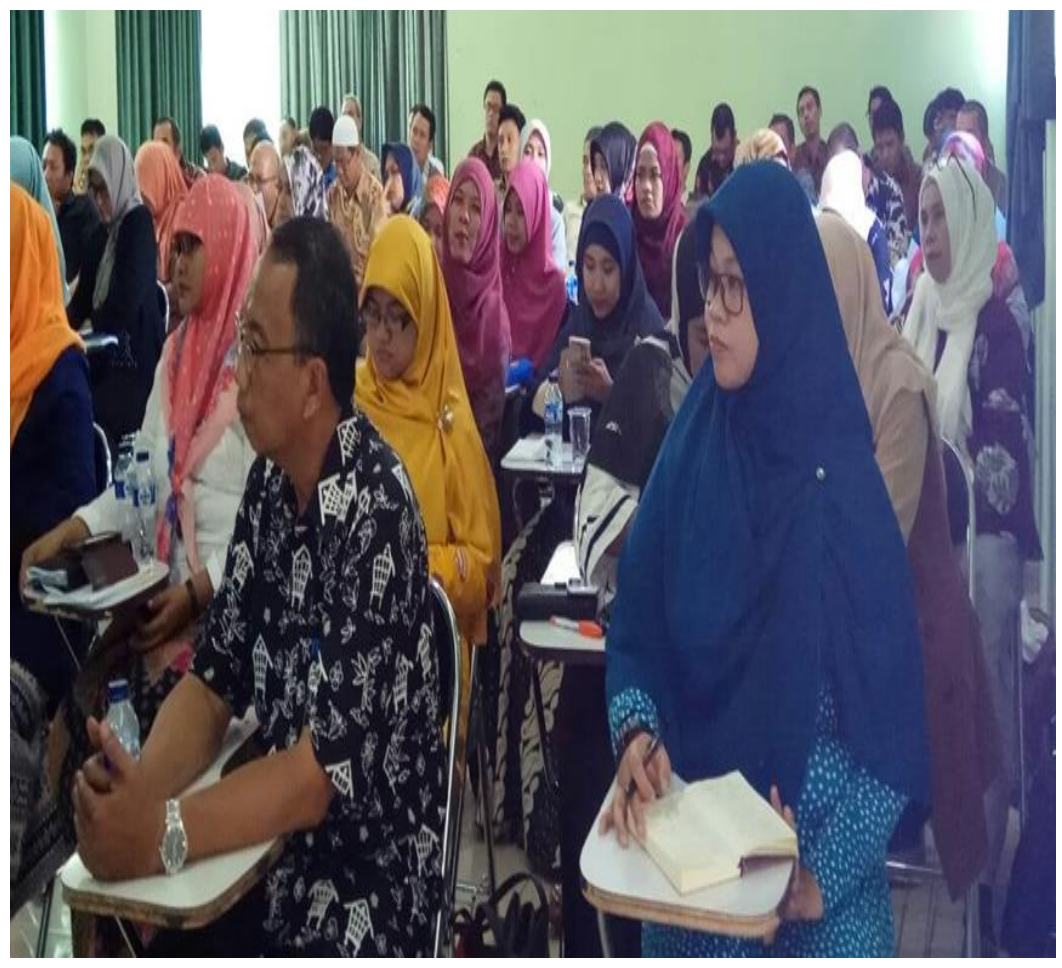

Gambar 2. Peserta PKM Menyimak Pemateri 


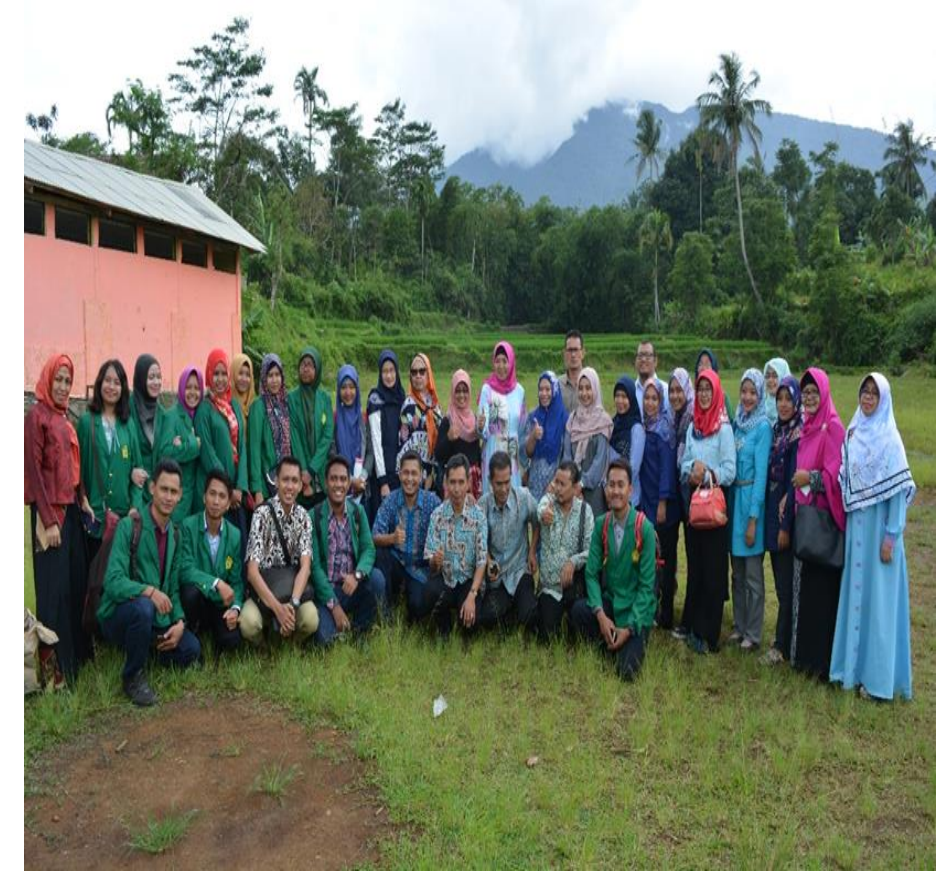

Gambar 3. Foto Bersama Tim PKM

\section{Simpulan dan Tindak Lanjut}

Kesimpulan yang dapat ditarik dari pelaksanaan program Pengabdian Kepada Masyarakat (PKM) ini adalah sebagai berikut: Kegiatan ini dapat meningkatkan keterampilan guru SDN dalam merancang serta melaksanakan pembelajaran yang lebih atraktif dan merangsang keaktifan siswa SD. Program ini juga meningkatkan motivasi peserta untuk meningkatkan wawasan dan pengetahuan terkait metode pembelajaran secara umum, serta memacu peserta untuk meningkatkan profesionalisme mereka dalam pelaksanaan pembelajaran. Media pembelajaran Matematika dapat menjadi alternatif solusi bagi guru SDN Jatimekar 02 untuk meningkatkan kualitas pembelajaran serta mencapai tujuan dari pembelajaran.

Peserta pelatihan diharapkan dapat menerapkan metode pembelajaran yang sesuai di kelas masing-masing, serta dapat melatih guru-guru sejawatnya. Pihak-pihak pengelola pendidikan seperti Kepala UPTD Pendidikan, Pengawas SD, serta Kepala SD agar memberikan kesempatan yang lebih banyak kepada guru-guru SD untuk meningkatkan kualitas pembelajaran. 


\section{Daftar Pustaka}

Wahid, A. (2018). Jurnal Pentingnya Media Pembelajaran Dalam Meningkatkan Prestasi Belajar. Istiqra: Jurnal Pendidikan dan Pemikiran Islam, 5(2).

http://jurnal.umpar.ac.id/index.php/istiqra/article/view/461

Novitasari, D. (2016). Pengaruh penggunaan multimedia interaktif terhadap kemampuan pemahaman konsep matematis siswa. FIBONACCI: Jurnal Pendidikan Matematika Dan Matematika, 2(2), 8-18. https://doi.org/10.24853/fbc.2.2.8-18

Priatna, N., \& Yuliardi, R. (2018). Pembelajaran Matematika. Bandung: PT Remaja Rosdakarya..

Suparno, P. (2002). Pendidikan Budi Pekerti di Sekolah, Suatu Tinjauan Umum. Yogyakarta: Penerbit Kanisius 